\title{
Performance as a Classification Criterion of Tourist Origins and Destinations
}

\author{
PAULO ÁGUAS, PAULO RITA and JORGE COSTA
}

\begin{abstract}
Portfolio analysis has been used as a tool for the study of market segments, namely of tourist destinations. However, a review of the literature did not identify a single case where the performance variable is adjusted to the nature of the object. This article presents a performance proxy that enables a direct comparison between generating countries (origins) and between destinations. The proposed tool is a component of a model for the identification of priority market segments. The instrument is applied to the 15 member states of the European Union (before its expansion on 1 May 2004), for the period from 1996 to 2001.
\end{abstract}

\section{INTRODUCTION}

The definition of performance variables, which can be used as indicators of the results obtained/to be obtained, is a fundamental prerequisite of any evaluation process. Portfolio analysis has been used as a tool for the study of market segments, namely of tourist destinations. However, a review of the literature did not identify a single case where the performance variable is adjusted to the nature of the object. In fact, contrary to many other situations, the use of performance variables in absolute terms does not appear to be the best solution given that the total volume is conditioned by the size of the territory and, above all, by the number of inhabitants. In other words, for a certain level of socio-economic development, larger countries (in terms of size and number of inhabitants) will tend to have higher absolute values.

Besides this, the empirical studies reviewed contain little, or no, information about competition, being temporally static. Although in some cases growth rate is used as a variable, thus presupposing the consideration of two magnitudes at two different times, more than one register per object is never considered, meaning that evolutive analyses are not viable.

Consequently, a performance proxy was developed which enables a direct comparison between generating countries (origins) and between destinations, regardless

Paulo Águas, Universidade do Algarve, Escola Superior de Gestão, Hotelaria e Turismo, Estrada da Penha, Campus da Penha, 8005-139 Faro, Portugal. Email: paguas@ualg.pt; Paulo Rita, Instituto Superior das Ciências do Trabalho e da Empresa, Av. das Forças Armadas, 1649-026 Lisboa, Portugal. Email: paulo. rita@ iscte.pt; Jorge Costa, Universidade Fernando Pessoa, Praça 9 de Abril, 349, 4249-004 Porto, Portugal. Email: jcosta@ufp.pt

The Service Industries Journal, Vol.26, No.3, April 2006, pp.1-17

ISSN 0264-2069 print/1743-9507 online

DOI: 10.1080/02642060600571099 (C) 2006 Taylor \& Francis 
of the number of inhabitants. The selection of the performance proxy can depend on the object of study. In any case, it should always permit the evaluation, in general terms, of the results obtained by the destination for the set of origins under analysis and the results generated by the origin for the set of destinations under study.

The proposed tool is a component of a model for the identification of priority market segments, and is constituted by a system of orthogonal axes which produces four quadrants that are distinct in terms of intensity (axis OY) and growth (axis OX) of tourist flows. The tool, like the model, can be applied to any type of destination (city, region or country) and to any market segmentation criterion (geographic, demographic, behavioural, psychographic or other).

In the study reported here, the instrument is applied to the 15 member states of the European Union (before its expansion on 1 May 2004), for the period from 1996 to 2001. Eurostat was the sole source of data for the study.

The UK and Ireland are the countries classified as 'Progressing Origins'. With 16.8 per cent of the population, they increased their contribution from 17.7 per cent to 21.9 per cent and are responsible for 38.7 per cent of the growth that occurred between 1996 and 2001.

Spain, Greece and Ireland are the countries classified as 'Progressing Destinations'. With 14.4 per cent of the population, they increased their share of the market from 21.5 per cent to 24.2 per cent, capturing 35.1 per cent of the growth that occurred between 1996 and 2001.

\section{FORMULATION OF THE RESEARCH PROBLEM}

Generally speaking, any research activity has multiple objectives, namely to describe, explain, understand, predict, criticise and/or analyse knowledge or social phenomena [Ghauri et al., 1995]. According to Pizam [1994], all research processes begin with the identification and selection of a research area, which may arise from issues of a scientific or practical nature. For the study reported here, the formulation of the research problem comes from both scientific concerns, i.e. an interest in market segmentation in the context of tourist destinations, and also concerns of a more practical nature, namely the gathering of information that can support decision making when there is a choice between several alternatives.

The main objective in developing a model to identify priority market segments in tourism is to provide an answer to the following research question: 'How can priority market segments be identified?' The research question was refined by means of a review of the literature and, besides filling the gap detected, it potentially leads to the definition of the variables to use, presenting them in the stages of the formulation and operationalisation of the model.

It is hoped that the answer obtained will contribute to an increase in knowledge about the issue and, simultaneously, will constitute a support tool for decision making. Finally, we should not forget originality: Ghauri et al. [1995] consider originality to be synonymous with the creation of new dimensions to a corpus of existing knowledge - dimensions which can be obtained through the application of new perspectives, hypotheses and methods, which indeed is what we hope this study will achieve. 


\section{LITERATURE REVIEW}

The formulation of the research problem and the proposal of the model were grounded in a review of the literature on market analysis (segments), both in general terms and as applied to tourism. Below are the main implications of the findings regarding knowledge about the present state of and recent developments in research on this topic:

- Targeting is the stage in the segmentation process which has warranted the least attention by researchers and which therefore most needs further study [Sarabia, 1996].

- The evaluation of market segments constitutes an indispensable prerequisite for the identification of priority targets [Mazanec, 1986a]. Their selection presupposes a previous evaluation.

- Competitiveness and attractiveness have been used to evaluate tourist destinations and generating markets, but not always in an integrated way [e.g. Mazanec, 1986b; Wynegar, 1994; Perdue, 1996].

- The competitiveness of a destination does not depend solely on instrumental variables. For example, location, climate and culture in a broad sense, among other things, constitute variables which are not susceptible to any type of intervention on the part of the destination's decision makers aiming for an increase in competitiveness. Thus in some cases variables have been introduced into the competitiveness sphere which are not controllable (instrumental) by the decision makers (e.g. distance [Mazanec, 1995]; the same language as the origin [Henshall and Roberts, 1985]), or which constitute a consequence of the degree of competitiveness (e.g. market share [Henshall and Roberts, 1985]).

- Portfolio analysis has become more widely used as an instrument for the study of market segments, specifically for tourist destinations [e.g. Henshall and Roberts, 1985; Mazanec, 1986a, 1995; Papadopoulos, 1989; Calantone and Mazanec, 1991; McKercher, 1995; Zins, 1999]. Its main aim is to identify the market segments with the greatest potential.

- The principal gaps in portfolio analysis are the following:

1. In no case is the performance variable adjusted to the nature of the object. In fact, contrary to many other situations, the use of performance variables in absolute terms does not appear to be the most advisable means, given that the total volume is conditioned by the size of the territory and, above all, by the number of inhabitants. In other words, for a certain level of socio-economic development, the largest countries, in terms of land area and population, will tend to have the highest values in absolute terms.

2. Some cases are limited to a transposition of standardised portfolio models, i.e. the BCG and McKinsey models. In the case of the BCG, Calantone and Mazanec [1991] and Mazanec [1995] use the original variables (industrial growth rate and relative market share).

3. Except for the cases of the application of the BCG model with the abovementioned original variables, there appear to be difficulties in obtaining data 
to gauge competitiveness and attractiveness. In Papadopoulos' [1989] study, the model is merely formulated and the respective operationalisation is not presented. In the case of McKercher [1995], the illustration given of the model develops a classification of the generating countries in the different lifecycle phases without any reference to the variables used to effect.

4. Wherever multifactorial axes are used, the values of competitiveness and attractiveness are obtained through additive models in which the weighting of the variables is achieved through subjective processes, i.e. through the consultation of specialists or by using the researchers' own judgement.

5. All the models presuppose a relationship between performance (dependent variable) and competitiveness and attractiveness (independent variables). However, this relationship is never tested in the empirical studies.

6. Despite assuming the objective of identifying priority markets, the empirical studies are limited to a characterisation of the situation (diagnostic) in terms of performance, competitiveness and attractiveness. The markets are not in fact subjected to any form of classification (typification).

7. The models have a reduced, or even non-existent, level of information about competition. When this happens, it is substantiated in the inclusion of variables relating to competitive pressure, i.e. the promotional expenditure of competitors.

8. All the empirical studies reviewed are temporally static. Although in some cases the growth rate variable is used [e.g. Calantone and Mazanec, 1991; Mazanec, 1995], thus presupposing the consideration of two magnitudes in two distinct moments in time, more than one register per object is never considered, which makes evolutional analyses unviable.

\section{FORMULATION OF THE MODEL}

The proposed model for identifying priority market segments (Figure 1) contains both deductive and inductive elements and is based on the concepts of Performance, Competitiveness and Attractiveness. Processes in which the nature of the relationships between observations, facts, hypotheses and models assume a dialectical character between the conceptualisation of the deductive method and the empiricism of the inductive are designated by Ryan [1995] as functional.

The principal characteristics of the model are as follows:

- Performance: the performance proxy is a relative value which allows direct comparison between origins and destinations, regardless of the number of inhabitants.

- Market Segments and Destinations: an analysis is carried out simultaneously for a set of $m$ destinations and of $n$ segments (generating countries), which make up the relevant market under study.

- Grouping of Market Segments: the classification into homogenous groups is carried out using attractiveness variables, with the requirement that they present a statistically significant relationship with the performance proxy of the market segments. 
FIGURE 1 MODEL FOR THE IDENTIFICATION OF PRIORITY MARKET SEGMENTS

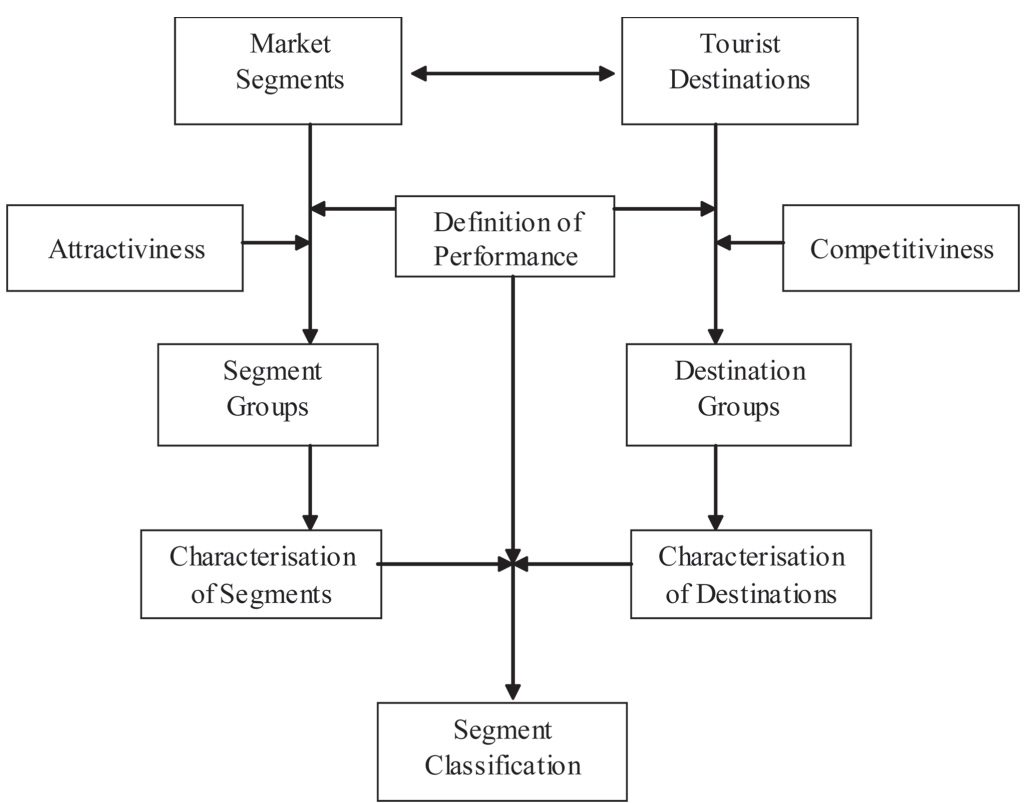

- Grouping of Destinations: the classification into groups (of competing destinations) is obtained through the degree of similarity of their performances in the market segments under consideration, which constitute an indicator of the different competitive positions.

- Characterisation of Market Segments and Destinations: this arises from the conjugation of the results obtained in the phases of performance analysis and grouping of the market segments and destinations.

- Classification of Market Segments: the classification is performed through evaluation of the contribution of the market segments in the evolution of the destinations.

\section{OPERATIONALISATION OF THE MODEL}

The operationalisation of the model requires the following elements/key stages to be made explicit: performance; grouping of the market segments; grouping of the destinations; characterisation of the market segments and destinations; and the classification of the market segments.

\section{Destination and Market Segment Performance}

The selection of the performance proxy may depend on the object of study. In any case, it should always permit us to evaluate, in general terms, the results obtained by the destination in the set of segments under analysis along with the results 
given by the segment (origin) for the set of destinations being studied. Potential proxies could be: number of visitors; number of tourists; number of overnight stays; receipts (in the context of the destination)/expenditure (in the context of the origin).

The variables can be expressed as relative values. In an initial phase, the absolute values should be transformed into values per capita, using the resident population (number of inhabitants) of the destination/origin under analysis as the reference point. Then these values are converted into an index number, taking as the reference the per capita value of the universe under study (the set of market segments and of destinations).

$$
I D_{i}=\frac{D_{i} / P_{i}}{\sum_{i=1}^{15} D_{i} / P_{i}} * 100
$$

where

$\mathrm{ID}_{i}$ is the index of the proxy per capita for the generating/receiving country $i$

$\mathrm{D}_{i}$ is the absolute value of the proxy registered/generated in country $i$

$\mathrm{P}_{i}$ is the number of inhabitants in country $i$

Besides measuring the performance level at a determined moment in time, recent evolution should also be assessed. This assessment can be carried out by means of the trend analysis of the performance proxy, which requires a chronological series of data.

\section{Grouping the Market Segments}

The attractiveness of market segments should be described by using variables that have statistically significant relationships with the performance proxy chosen. To this effect, the performances of the origin, and not the destination, are considered. The main objective is to characterise attractiveness by means of the grouping of market segments into qualitative categories.

The stages in the procedure are as follows:

- Selection of the market segments to be analysed: the choice is conditioned by the availability of data for the performance proxy.

- Pre-selection of the variables to measure attractiveness: the universe of choice is constituted by variables that are official statistics and which reflect situations not controlled or influenced by the destination.

- Selection of the variables to measure attractiveness: only variables able to explain the performance proxy are chosen. The total number of selected variables must be lower than the number of objects (segments) to be classified. Correlation and regression analysis are the statistical tools used to obtain the results.

- Classification of the segments: the grouping of the segments is achieved by means of applying cluster analysis to factors or variables identified from those initially selected. 
- Characterisation of the groups of segments: the principal differences between the groups of segments is detected by carrying out a discriminant analysis. In this way, it is possible to identify the causes of eventual changes in the segment grouping, which appear to be pertinent despite the fact these are not instrumental variables for the destinations.

- Validation of the segment grouping: for the results to be acceptable the performance proxy needs to present an inter-segment dispersion that is greater than the intra-segment dispersion. This can be tested by analysis of variance. It could be that this validation process requires the revision of the initially selected variables, and it should be noted that, in some cases, the process might not have a solution.

\section{Grouping the Destinations}

The destinations can be classified in groups (clusters) according to the degree of similarity in their performances in the market segments under analysis, which then permits us to identify the competing destinations. Thus the main competing destinations are the countries in the same group.

As with the grouping of the market segments, multivariate statistical techniques should be applied. If satisfactory results are not obtained, the only consequence is that it is then impossible to identify the main competing destinations - the viability of the application of the model is not threatened.

The stages are as follows:

- Calculation of the relative importance of the origins for the destinations: for each destination $j$ the calculation of the distribution of the relative frequencies for the $n$ market segments under study is made by applying the following formula:

$$
\mathrm{DR}_{j i}=\left[\left(\mathrm{Dji} / \sum_{\mathrm{i}=1}^{\mathrm{n}} \mathrm{D}_{\mathrm{ji}}\right)\right]
$$

where

$\mathrm{DR}_{j i}=$ the relative importance of destination $j$ for origin $i$ at the moment in time $t$ $\mathrm{D}_{j i}=$ the value of destination $j$ in origin $i$ at the moment in time $t$.

- Classification of the destinations: the groupings of the destinations are obtained through the application of a cluster analysis to the relative importance variable $\left(\mathrm{DR}_{j i}\right)$.

\section{Characterisation of the Market Segments and the Destinations}

The characterisation of the market segments and the destinations should be carried out by using the results from the previous stages, which means that it is only possible to establish the dimensions of the analysis, as well as the results to be achieved, through the actual application of the model. In any case, it can be expected that the registers obtained for the performance proxy, the market shares, the performance evolution and the market segment and destination clusters constitute the starting point for this stage of the model. 


\section{Classification of the Market Segments}

The classification of the market segments is carried out by evaluating their contribution to the evolution of the destinations. It is suggested that the evolution of the destinations (the dependent variable) is subjected to a qualitative classification resulting from the preceding characterisation. As for the independent variables, they constitute combinations of market segments (origins), also resulting from the previously executed characterisation, and are expressed in growth rates or in contributions.

\section{APPLICATION OF THE MODEL}

In this paper only the results obtained in the market segment and destination characterisation stage are presented. First, we state the object of analysis and the objectives of this component of the research.

\section{Object of Analysis}

Normally the choice of the object of analysis is conditioned by the problem identified as forming the basis of the study. In many cases, the object of analysis constitutes a central role in the research process. However, this is not the case for the research undertaken here, where the object merely represents a means to an end. Thus the choice is restricted only by the availability of data, and its nature (whether city, region or country) is a matter of indifference.

Given that in the presentation of the model we recommended that official statistics should be used as they are considered to provide the best guarantee of comparability and reliability, our choice was the member states of the European Union, before its enlargement on 1 May 2004. In effect, the process of European integration has led to a harmonisation of statistical production, which has been regulated by Community Directives.

In its turn, the type of data available for destinations also conditions the choice of market segments. Here, the geographical criterion is the sole possibility, since the variable selected for the performance proxy (overnight stays in hotels) is only registered by country of residence. Indeed, the whole Eurostat database is organised by NUTS (Nomenclature of Territorial Units for Statistics), an intrinsic feature of official statistics. This nomenclature is aimed at the gathering, organisation and dissemination of regional, harmonised statistics in the EC.

However, it is important to stress that the proposed model can be applied to any type of destination (city, region or country) and to any market segmentation criteria (demographic, geographic, behavioural, psychographic or any other). In the case of the destination it is necessary to consider more than one at the same time, this being the only way to assure the analysis of competitiveness in relative terms. In the case of the market segments, they must be common to all the destinations considered: in other words, there cannot be any empty cells in the data matrix of segments/destinations.

Given that the object of analysis does not assume a central role in this research process, we do not consider an exhaustive characterisation of it to be justified. Therefore Table 1 is presented as a mere informative, contextualising illustration 
TABLE 1

OVERNIGHT STAYS IN HOTEL OR SIMILAR ESTABLISHMENTS IN THE EU-15, BY ORIGIN AND BY MEMBER STATE, 2001

\begin{tabular}{|c|c|c|c|c|c|c|}
\hline \multirow[b]{2}{*}{$\begin{array}{l}\text { Member } \\
\text { states }\end{array}$} & \multicolumn{4}{|c|}{ Overnights registered by type of origin } & \multirow[b]{2}{*}{$\begin{array}{l}\text { Overnights } \\
\text { generated } \\
\text { in other } \\
\text { member } \\
\text { states }\end{array}$} & \multirow[b]{2}{*}{$\begin{array}{c}\text { Exp./Imp. } \\
\text { ratio of } \\
\text { overnight } \\
\text { stays in } \\
\text { the EU* }(\%)\end{array}$} \\
\hline & Total & $\begin{array}{c}\text { Domestic } \\
(\%)\end{array}$ & $\begin{array}{c}\text { Other } \\
\text { member } \\
\text { states } \\
(\%)\end{array}$ & $\begin{array}{c}\text { Outside } \\
\text { the EU } \\
(\%)\end{array}$ & & \\
\hline Austria & $72,553,523$ & 25.5 & 62.8 & 11.7 & $11,940,951$ & 381.6 \\
\hline Belgium & $14,068,593$ & 28.8 & 55.1 & 16.1 & $20,991,448$ & 36.9 \\
\hline Denmark & $9,140,317$ & 50.2 & 28.7 & 21.1 & $7,666,542$ & 34.2 \\
\hline Finland & $13,557,149$ & 72.9 & 14.3 & 12.8 & $3,933,856$ & 49.1 \\
\hline France & $191,227,250$ & 60.4 & 26.0 & 13.6 & $30,202,963$ & 164.4 \\
\hline Germany & $197,072,725$ & 83.3 & 8.8 & 7.9 & $147,350,350$ & 11.7 \\
\hline Greece & $61,007,777$ & 24.2 & 61.5 & 14.3 & $2,396,789$ & $1,566.4$ \\
\hline Ireland & $25,652,000$ & 30.4 & 48.5 & 21.2 & $6,095,048$ & 204.0 \\
\hline Italy & $238,881,737$ & 58.0 & 28.2 & 13.8 & $26,254,355$ & 256.9 \\
\hline Luxembourg & $1,221,852$ & 6.0 & 78.1 & 15.9 & $1,583,276$ & 60.3 \\
\hline Netherlands & $28,563,000$ & 47.6 & 34.0 & 18.4 & $28,951,460$ & 33.5 \\
\hline Portugal & $33,562,591$ & 29.8 & 60.6 & 9.6 & $4,041,435$ & 503.5 \\
\hline Spain & $228,681,560$ & 37.3 & 53.9 & 8.8 & $13,495,681$ & 912.8 \\
\hline Sweden & $21,663,570$ & 77.3 & 11.1 & 11.7 & $12,843,819$ & 18.7 \\
\hline $\begin{array}{l}\text { United } \\
\text { Kingdom }\end{array}$ & $184,200,996$ & 73.0 & 13.5 & 13.5 & $105,912,539$ & 23.4 \\
\hline EU-15 & $1,321,054,640$ & 55.9 & 32.1 & 12.1 & $423,660,512$ & 100.0 \\
\hline
\end{tabular}

* Overnight stays registered with origin in other member states (exportations) $\div$ Overnight stays generated in other member states (importations) $\times 100 \%$.

Source: Eurostat (2003), data adapted by authors.

of the data on overnight stays in hotels and similar establishments in the 15 member states of the EU in 2001.

As can be seen, more than half of the overnight stays registered in the EU (55.9 per cent) are generated within the same country (domestic tourism). In relative terms, there is less domestic tourism in the more southern European countries and in those with a small land area, and more in the larger countries, the more peripheral countries and the more northern countries. Of course the global percentages of overnight stays with international origin (inbound tourism) represent the complementary value to domestic tourism (internal tourism $=$ domestic tourism + inbound tourism), thus making it fitting to break down the registers into those originating inside and outside the EU.

However, despite the ratio of overnight stays originating in other EU countries (32.1 per cent) and those originating outside the EU (12.1 per cent) being, in global terms, almost 3:1, some countries in fact have a ratio of close to 1:1 (Sweden, the UK and Finland) whilst for others it is more than 5:1 (Portugal, Spain and Austria). This shows the unequal importance of the non-EU origin. In only two countries (Ireland and Denmark) the non-EU origin reaches a figure of just over 20 per cent. Overall, 88 per cent of overnight stays in the EU are generated within the EU. 
The export/import ratio of overnight stays (EU) indicator shows a high degree of dispersion, and therefore inequalities, amongst the EU member states. In effect, the southern countries present an export/import ratio of more than 100 per cent. With the exception of Austria and Ireland, the other member states further to the north are net importers as they generate more overnights than they receive. This finding indicates that, generically, north $\Rightarrow$ south is the prevailing direction of the tourist flows within the EU.

Finally, it can be noted that the five biggest countries in terms of population generated 72.8 per cent and captured 78.7 per cent of the total overnight stays within the EU in 2001. In this year, Germany, the UK, France, Italy and Spain, whose collective population was 299.1 million, accounted for 79.2 per cent of the 378 million EU inhabitants [Eurostat, 2003].

\section{Objectives of the Empirical Study}

The nature of the object of application of the model leads to the establishing of the following specific objectives:

1. The evaluation of the relative positions of the overnight stays registered (destinations) and generated (origins) in the EU MS.

2. The trend analysis of the performance of the EU MS, as both destinations and generating countries.

3. The identification of groups of competing destinations within the EU.

4. The characterisation of the EU MS, as generating countries and as destinations.

Results: Characterisation of Market Segments and Destinations

In view of the findings obtained in the various stages of the process regarding performance and grouping - which are not the object of a detailed examination in this paper - the characterisation of market segments and destinations is carried out for 15 generating countries (market segments) and 15 destinations, using the following variables:

- Overnight stay index: intense $(\geq 100)$; or soft $(\langle 100)$.

- Growth in overnight stays: strong (above EU average); or weak (below EU average).

- Market share: from 0.0 per cent to 100.0 per cent.

- Trend performance: $\mathrm{G}=$ growth; $\mathrm{D}=$ decreasing; or $\mathrm{WT}=$ without trend.

- Market segments and destinations groupings: $\mathrm{N}=$ northern member states; $\mathrm{S}=$ southern member states.

Market segments. A graphic representation (Figure 2) of the contents of Table 2 was made. The Growth in Overnight Stays (GOS) and Overnight Stay Index (OSI) variables constitute the axes OX and OY respectively.

The definition of the quadrants was carried out using the average values of the overnight stay index (100, on account of the nature of the variable) and the growth in overnight stays registered in hotels and similar establishments in the EU with 
FIGURE 2

CHARACTERISATION OF MARKET SEGMENTS, 1996-2001

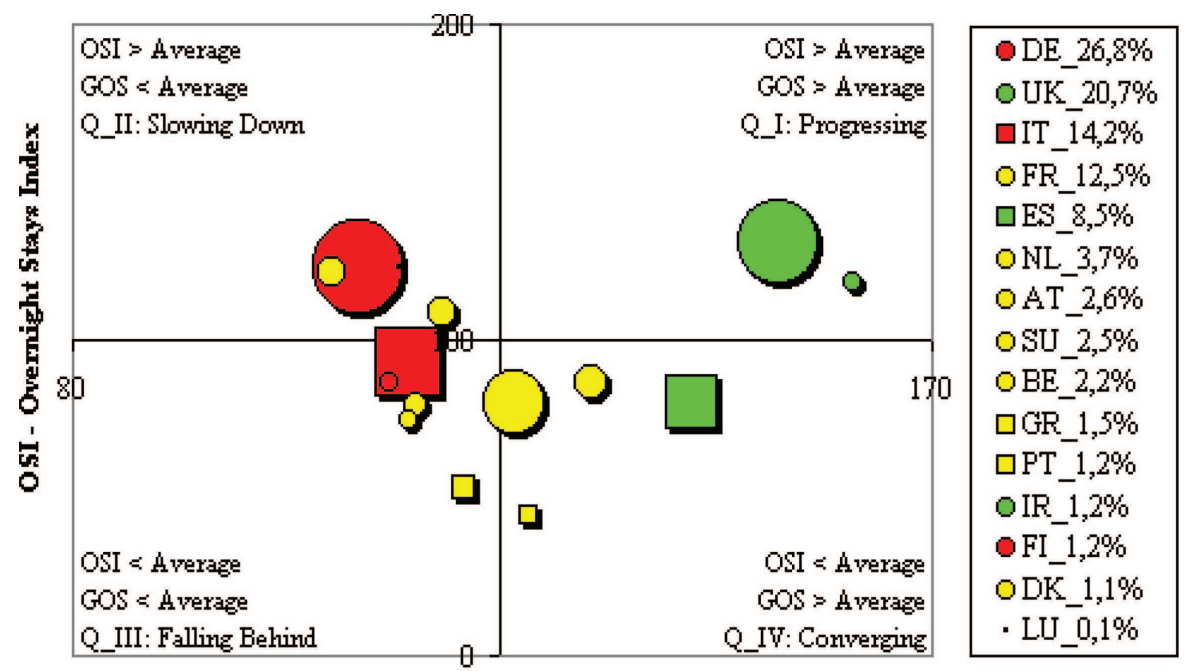

GOS - Growth in Overnight Stays

origin in the EU (124.8, in index), between 1996 and 2001. The combination of these two variables leads to the following quadrants:

- Q_I: Progressing - overnight stay index and growth in overnight stays above average.

TABLE 2

CHARACTERISATION OF MARKET SEGMENTS, 1996-2001

\begin{tabular}{|c|c|c|c|c|c|}
\hline $\begin{array}{l}\text { Market } \\
\text { segment }\end{array}$ & $\begin{array}{c}\text { Overnight } \\
\text { stay } \\
\text { index, } 2001\end{array}$ & $\begin{array}{l}\text { Growth in } \\
\text { overnight } \\
\text { stays, } \\
\text { 1996-2001 }\end{array}$ & $\begin{array}{l}\text { Market } \\
\text { share, } \\
2001(\%)\end{array}$ & $\begin{array}{c}\text { Trend, } \\
\text { 1996-2001 }\end{array}$ & $\begin{array}{c}\text { Group, } \\
\text { 1996-2001 }\end{array}$ \\
\hline Austria & 121.8 & 107.1 & 2.6 & WT & $\mathrm{N}$ \\
\hline Belgium & 79.4 & 115.9 & 2.2 & WT & $\mathrm{N}$ \\
\hline Denmark & 74.6 & 115.1 & 1.1 & WT & $\mathrm{N}$ \\
\hline Finland & 86.8 & 113.2 & 1.2 & $\mathrm{D}$ & $\mathrm{N}$ \\
\hline France & 80.4 & 126.3 & 12.5 & WT & $\mathrm{N}$ \\
\hline Germany & 123.2 & 110.0 & 26.8 & $\mathrm{D}$ & $\mathrm{N}$ \\
\hline Greece & 52.8 & 120.9 & 1.5 & WT & $\mathrm{S}$ \\
\hline Ireland & 118.1 & 161.6 & 1.2 & G & $\mathrm{N}$ \\
\hline Italy & 92.7 & 115.2 & 14.2 & $\mathrm{D}$ & $\mathrm{S}$ \\
\hline Luxembourg & 122.7 & 114.1 & 0.1 & $\mathrm{D}$ & $\mathrm{N}$ \\
\hline Netherlands & 86.6 & 134.4 & 3.7 & WT & $\mathrm{N}$ \\
\hline Portugal & 44.5 & 127.7 & 1.2 & WT & $\mathrm{S}$ \\
\hline Spain & 80.1 & 144.9 & 8.5 & G & $\mathrm{S}$ \\
\hline Sweden & 108.4 & 118.6 & 2.5 & WT & $\mathrm{S}$ \\
\hline United Kingdom & 130.6 & 153.8 & 20.7 & $\mathrm{C}$ & $\mathrm{N}$ \\
\hline
\end{tabular}


- Q_II: Slowing down - overnight stay index above average and growth in overnight stays below average.

- Q_III: Falling behind - overnight stay index and growth in overnight stays below average.

- Q_IV: Converging - overnight stay index below average and growth in overnight stays above average.

The other variables are expressed as follows:

- Market share - through the area size of each object (market segment).

- Trend performance - through the colour of the area: $\mathrm{C}=$ green; $\mathrm{D}=$ red; $\mathrm{ST}=$ yellow.

- Group - through shape: $\mathrm{N}=$ circle; $\mathrm{S}=$ square.

Q_I and Q_II are composed exclusively of market segments, six in total, which integrate the group of northern member states. Whilst the market segments in Q_I (progressing) show a growth trend (the UK and Ireland), in Q_II (slowing down) there are situations of decrease (DE and AT) co-existing with those without trend (Luxembourg and Sweden).

All the market segments of the group of southern member states are in the 'soft' quadrants, Q_III and Q_IV, which also include five market segments from the northern member states group. Each of these two quadrants has market segments from both groups, northern and southern member states.

The market segments without trend, regardless of which group they belong to, are in one or other of the 'soft' quadrants, while those with a decreasing trend are in Q_III and the only one with a growth trend is in Q_IV (converging).

Table 3 illustrates how, year on year throughout the period, there is a relative stability in the classification of the segments. The changes to the quadrant compared to the

TABLE 3

CHARACTERISATION OF THE MARKET SEGMENTS BY QUADRANT, 1997-2001 (BASE YEAR 1996)

\begin{tabular}{llllll}
\hline Market segment & 1997 & 1998 & 1999 & 2000 & 2001 \\
\hline Austria & Q_II & Q_I & Q_II & Q_II & Q_II \\
Belgium & Q_IV & Q_IV & Q_IV & Q_III & Q_III \\
Denmark & Q_IV & Q_IV & Q_IV & Q_III & Q_II \\
Finland & Q_IV & Q_IV & Q_III & Q_III & Q_III \\
France & Q_III & Q_IV & Q_IV & Q_III & Q_IV \\
Germany & Q_II & Q_II & Q_II & Q_II & Q_II \\
Greece & Q_IV & Q_IV & Q_III & Q_III & Q_III \\
Ireland & Q_III & Q_I & Q_I & Q_I & Q_I \\
Italy & Q_III & Q_I & Q_III & Q_III & Q_III \\
Luxembourg & Q_II & Q_II & Q_II & Q_II & Q_II \\
Netherlands & Q_IV & Q_IV & Q_IV & Q_IV & Q_IV \\
Portugal & Q_IV & Q_IV & Q_IV & Q_IV & Q_IV \\
Spain & Q_IV & Q_IV & Q_IV & Q_IV & Q_IV \\
Sweden & Q_II & Q_I & Q_II & Q_II & Q_II \\
United Kingdom & Q_I & Q_I & Q_I & Q_I & Q_I \\
\hline
\end{tabular}


TABLE 4

CONTRIBUTIONS OF THE MARKET SEGMENTS BY QUADRANTS (\%)

\begin{tabular}{lcccc}
\hline $\begin{array}{l}\text { Market } \\
\text { segments }\end{array}$ & $\begin{array}{c}\text { Contribution } \\
\text { in 1996 }\end{array}$ & $\begin{array}{c}\text { Contribution } \\
\text { in 2001 }\end{array}$ & $\begin{array}{c}\text { Contribution } \\
\text { to Growth 96-01 }\end{array}$ & $\begin{array}{c}\text { Population } \\
\text { in 2001 }\end{array}$ \\
\hline Quadrant I & 17.7 & 21.9 & 38.7 & 16.8 \\
Quadrant II & 36.3 & 32.1 & 15.3 & 26.4 \\
Quadrant III & 21.7 & 20.1 & 13.6 & 23.6 \\
Quadrant IV & 24.3 & 25.9 & 32.4 & 33.2 \\
\hline
\end{tabular}

previous year are marked in bold. Except for the cases of Ireland and Italy, the alterations to the quadrant are defined by the Growth in Overnight Stays variable, occurring horizontally between the quadrants I $\Leftrightarrow$ II and III $\Leftrightarrow$ IV.

The generating countries found in quadrants I and II (overnight stays index above average) make a contribution to the total overnight stays which is greater than the respective population, whereas the opposite happens with quadrants III and IV (Table 4). On the other hand, quadrants I and IV (growth in overnight stays above average) show progress in the contributions between 1996 and 2001, whilst the reverse happens in quadrants II and III. It should be noted that quadrants I and IV, with 50 per cent of the population, are responsible for 70.1 per cent of the growth in overnight stays between 1996 and 2001.

Destinations. The characterisation of the destinations is carried out in the same way as for the market segments. Table 5 presents the registers of the variables defined at the beginning of this section and which are represented in Figure 3.

TABLE 5

CHARACTERISATION OF THE DESTINATIONS, 1996-2001

\begin{tabular}{lccccc}
\hline Destination & $\begin{array}{c}\text { Overnight } \\
\text { stay } \\
\text { index, 2001 }\end{array}$ & $\begin{array}{c}\text { Growth in } \\
\text { overnight } \\
\text { stays, 1996-2001 }\end{array}$ & $\begin{array}{c}\text { Market } \\
\text { Share, } \\
\mathbf{2 0 0 1}(\mathbf{\%})\end{array}$ & $\begin{array}{c}\text { Trend, } \\
\mathbf{1 9 9 6 - 2 0 0 1}\end{array}$ & $\begin{array}{c}\text { Group-2001 } \\
\mathbf{1 9 9 6 - 2}\end{array}$ \\
\hline Austria & 256.6 & 100.7 & 5.5 & $\mathrm{D}$ & $\mathrm{N}$ \\
Belgium & 37.4 & 121.3 & 1.0 & $\mathrm{WT}$ & $\mathrm{N}$ \\
Denmark & 43.9 & 104.3 & 0.6 & $\mathrm{D}$ & $\mathrm{N}$ \\
Finland & 74.2 & 114.6 & 1.0 & $\mathrm{D}$ & $\mathrm{N}$ \\
France & 91.1 & 130.4 & 14.2 & $\mathrm{WT}$ & $\mathrm{N}$ \\
Germany & 71.8 & 114.0 & 15.6 & $\mathrm{D}$ & $\mathrm{N}$ \\
Greece & 161.2 & 131.0 & 4.5 & $\mathrm{WT}$ & $\mathrm{S}$ \\
Ireland & 172.0 & 140.8 & 1.7 & $\mathrm{WT}$ & $\mathrm{N}$ \\
Italy & 115.9 & 113.2 & 17.7 & $\mathrm{D}$ & $\mathrm{S}$ \\
Luxembourg & 76.1 & 116.4 & 0.1 & $\mathrm{D}$ & $\mathrm{N}$ \\
Netherlands & 47.5 & 145.2 & 2.0 & $\mathrm{WT}$ & $\mathrm{N}$ \\
Portugal & 96.2 & 117.6 & 2.6 & $\mathrm{D}$ & $\mathrm{S}$ \\
Spain & 169.1 & 143.1 & 17.9 & $\mathrm{WT}$ & $\mathrm{S}$ \\
Sweden & 70.1 & 114.2 & 1.6 & $\mathrm{WT}$ & $\mathrm{S}$ \\
United Kingdom & 86.6 & 141.2 & 13.7 & $\mathrm{WT}$ & $\mathrm{N}$ \\
\hline
\end{tabular}


FIGURE 3

CHARACTERIS ATION OF THE DESTINATIONS, 1996-2001

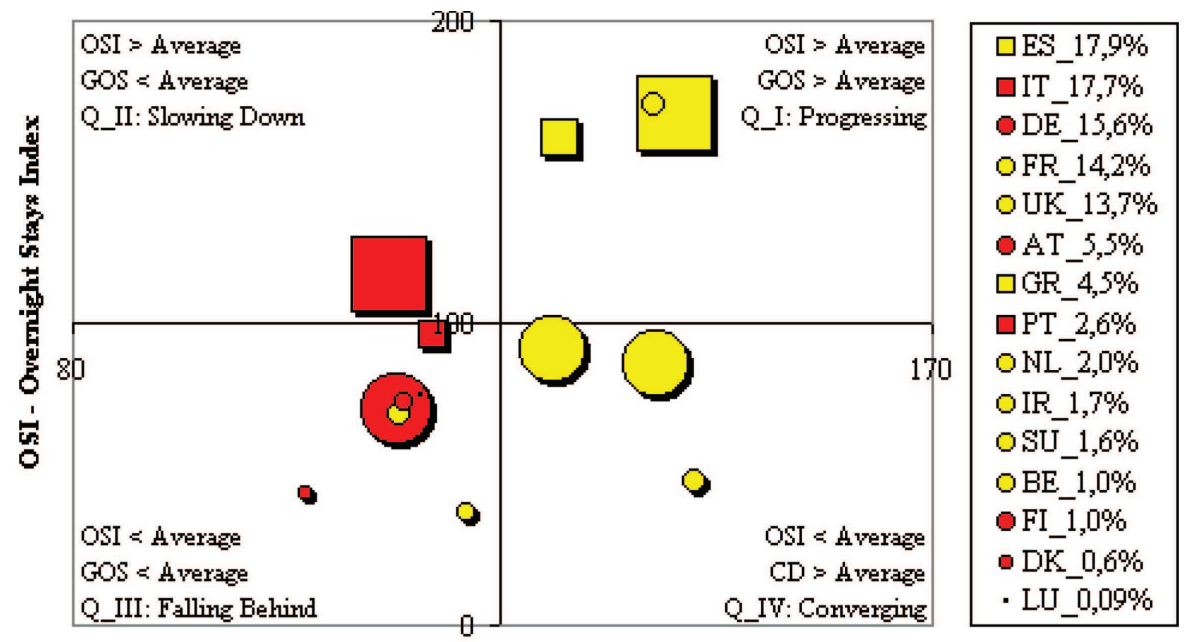

GOS - Growth in Overnight Stays

Figure 3 does not include the representation of Austria as the co-ordinate OY (256.6) exceeds the established limit of the scale. With the lowest register of growth in overnight stays (100.7), Austria is positioned in the second quadrant.

With the exception of Portugal, the destinations from the southern member states group are all in the 'intense' quadrants, Q_I and Q_II. On the other hand, just two of the ten destinations of the northern member states group are in those quadrants

TABLE 6

CHARACTERISATION OF THE DESTINATIONS BY QUADRANT, 1997-2001 (BASE YEAR 1996)

\begin{tabular}{llllll}
\hline Destination & 1997 & 1998 & 1999 & 2000 & 2001 \\
\hline Austria & Q_II & Q_II & Q_II & Q_II & Q_II \\
Belgium & Q_IV & Q_IV & Q_III & Q_III & Q_III \\
Denmark & Q_III & Q_III & Q_III & Q_III & Q_III \\
Finland & Q_IV & Q_IV & Q_III & Q_III & Q_III \\
France & Q_IV & Q_IV & Q_IV & Q_IV & Q_IV \\
Germany & Q_III & Q_III & Q_III & Q_III & Q_III \\
Greece & Q_I & Q_I & Q_I & Q_I & Q_I \\
Ireland & Q_I & Q_I & Q_I & Q_I & Q_I \\
Italy & Q_II & Q_II & Q_II & Q_II & Q_II \\
Luxembourg & Q_IV & Q_IV & Q_III & Q_III & Q_III \\
Netherlands & Q_IV & Q_IV & Q_IV & Q_IV & Q_IV \\
Portugal & Q_I & Q_I & Q_II & Q_III & Q_III \\
Spain & Q_I & Q_I & Q_I & Q_I & Q_I \\
Sweden & Q_III & Q_IV & Q_III & Q_III & Q_III \\
United Kingdom & Q_IV & Q_III & Q_III & Q_IV & Q_IV \\
\hline
\end{tabular}


TABLE 7

SHARES OF THE DESTINATIONS BY QUADRANT (\%)

\begin{tabular}{lcccc}
\hline Market segments & $\begin{array}{c}\text { Share in } \\
\mathbf{1 9 9 6}\end{array}$ & $\begin{array}{c}\text { Share } \\
\text { in 2001 }\end{array}$ & $\begin{array}{c}\text { Share in } \\
\text { growth } \\
\mathbf{1 9 9 6 - 2 0 0 1}\end{array}$ & $\begin{array}{c}\text { Population } \\
\text { in 2001 }\end{array}$ \\
\hline Quadrant I & 21.5 & 24.2 & 35.1 & 14.4 \\
Quadrant II & 26.4 & 23.2 & 10.6 & 17.5 \\
Quadrant III & 24.7 & 22.6 & 14.4 & 32.4 \\
Quadrant IV & 27.5 & 29.9 & 40.0 & 35.7 \\
\hline
\end{tabular}

(Ireland and Austria). The intense destinations of both groups are spread between quadrants Q_I and Q_II.

In Q_I (progressing) and Q_IV (converging), there are no destinations with a decreasing growth trend. In Q_II (slowing down) the two destinations show a decreasing growth trend. Finally, in Q_III (falling behind) we have the only case of co-existence between destinations with a decreasing growth trend and those without trend, the former being in the majority (five out of seven).

The distribution of the destinations by quadrant (Table 6) is more stable than that of the market segments (Table 3). The total number of quadrant changes, which are shown in bold, has decreased from 13 (market segments) to 9 (destinations) and the number of countries that do not show any alteration rises from 7 (market segments) to 9 (destinations). Except for the case of Portugal, the quadrant changes are defined by the Growth in Overnight Stays variable, occurring horizontally, especially between quadrants III $\Leftrightarrow$ IV. It should be pointed out that Portugal is the only destination to pass through three quadrants, from Q_I to Q_III, showing signs of falling off which are cause for some concern.

Just as with the generating countries, the destinations in quadrants I and II (overnight stay index above average) show a progression in their contributions from 1996 to 2001, contrary to those in quadrants II and III. It is worth noting that quadrants I and IV, with 50.1 per cent of the population, are responsible for 75.1 per cent of the growth in overnight stays between 1996 and 2001.

\section{CONCLUSIONS}

The application of a model for the identification of priority market segments based on, amongst other things, the criterion of Performance allows us to characterise the tourist flows between the $15 \mathrm{MS}$ of the EU (before its enlargement on 1 May 2004).

Objective 1: The evaluation of the relative positions of the overnight stays registered (destinations) and generated (origins) in the EU member states. In 2001, on the demand side, the UK (130.6), Germany (123.2), Luxembourg (122.7), Austria (121.8), Ireland (118.1) and Sweden (108.4) show above EU average consumption intensities (overnight stay index). On the supply side, the countries which show a 
higher than EU average production intensity (overnight stay index) are Austria (256.6), Ireland (172.0), Spain (169.1), Greece (161.2) and Italy (115.9).

Objective 2: The analysis of the trend performance of the EU member states, as both destinations and generating countries. Between 1996 and 2001, taking the EU average as a reference point, the generating countries Spain, Ireland and the UK show a growth trend in tourist flows, whilst Germany, Finland, Italy and Luxembourg show the opposite. As regards destinations, no cases of a growth trend were detected, but on the other hand Germany, Austria, Denmark, Finland, Italy, Luxembourg and Portugal all registered a decreasing trend. For the remaining countries, no sign of trend was detected.

Objective 3: The identification of groups of competing destinations within the $E U$. The countries under analysis form two groups, made up of ten and five countries respectively. The first group contains countries further to the north (Finland, Sweden, Denmark, Germany, Netherlands, United Kingdom, Ireland, Austria, Luxembourg and Belgium) whereas the countries in the second group are more southern (France, Italy, Spain, Portugal and Greece). In other words, the geographical factor appears to be determining in the identification of main competitors.

Objective 4: The characterisation of the EU member states, as generating countries and as destinations. Ireland and the UK are classified as 'progressing origins'. With 16.8 per cent of the population, their contribution rose from 17.7 per cent to 21.9 per cent and they were responsible for 38.7 per cent of the growth between 1996 and 2001.

Germany, Austria, Luxembourg and Sweden are classified as 'slowing down origins'. With 26.4 per cent of the population, their contribution fell from 36.3 per cent to 32.1 per cent. Collectively, they accounted for 15.3 per cent of the growth between 1996 and 2001.

Belgium, Denmark, Finland, Greece and Italy are classified as 'falling behind origins'. With 23.6 per cent of the population, their contribution dropped from 21.7 per cent to 20.1 per cent. They accounted for 13.6 per cent of growth between 1996 and 2001.

Spain, France, Netherlands and Portugal are classified as 'converging origins'. Their share of the population is 33.2 per cent and their contribution increased from 24.3 per cent to 25.9 per cent. They were responsible for 33.2 per cent of growth between 1996 and 2001.

Spain, Greece and Ireland are classified as 'progressing destinations'. With 14.4 per cent of the population, they increased their share from 21.5 per cent to 24.2 per cent, and together they accounted for 35.1 per cent of the growth from 1996 to 2001.

Austria and Italy are classified as 'slowing down destinations'. They have 17.5 per cent of the population and their share decreased from 26.4 per cent to 23.1 per cent whilst being responsible for 10.6 per cent of the growth from 1996 to 2001 .

Germany, Belgium, Denmark, Finland, Luxembourg, Portugal and Sweden are classified as 'falling behind destinations'. With 32.4 per cent of the population, their quota dropped from 24.7 per cent to 22.6 per cent whilst capturing 14.4 per cent of the growth in the period 1996 to 2001. 
France, the Netherlands and the UK are classified as 'converging destinations'. They account for 35.7 per cent of the population and their share increased from 27.5 per cent to 29.9 per cent. They were responsible for 40.0 per cent of the growth between 1996 and 2001.

\section{REFERENCES}

Calantone, R. and Mazanec, J. (1991) Marketing Management and Tourism, Annals of Tourism Research, 18(1), pp.101-19.

Eurostat (2003) New Cronos (on-line), available at http://europa.eu.int/newcronos (restricted access), 30 June 2003.

Ghauri, P., Kjell, G. and Kristianslund (1995), Research Methods in Business Studies: A Practical Guide, Englewood Cliffs, NJ: Prentice-Hall.

Henshall, B. and Roberts, R. (1985) Comparative assessment of tourist generating markets for New Zealand, Annals of Tourism Research, 12(2), pp.219-38.

Mazanec, J. (1986a) How to evaluate a travel market. Econometric modeling vs. multi-attribute decision making with management estimates, Centre des Hautes Études Touristiques - Série C, 48.

Mazanec, J. (1986b) Allocating an advertising budget to international travel markets, Annals of Tourism Research, 13(4), pp.609-34.

Mazanec, J. (1995) Análise da posição estratégica de cidades turísticas: um estudo para Lisboa, Revista Portuguesa de Gestão, II/III, pp.83-94.

McKercher, B. (1995) The destination-market matrix: a tourism market portfolio analysis model, Journal of Travel and Tourism Marketing, 4(2), pp.23-40.

Papadopoulos, S. (1989) A conceptual tourism marketing planning model: part 1, European Journal of Marketing, 23(1), pp.31-40.

Perdue, R. (1996) Target market selection and marketing strategy: the Colorado downhill skiing industry, Journal of Travel Research, 34(4), pp.39-46.

Pizam, A. (1994) Planning a tourism research investigation. In Ritchie and Goeldner (eds), Travel, Tourism and Hospitality Research, New York: John Wiley \& Sons, pp.91-103.

Ryan, C. (1995) Researching Tourist Satisfaction: Issues, Concepts, Problems, London: Routledge.

Sarabia, F. (1996) Model for market segments evaluation and selection, European Journal of Marketing, 30(4), pp.58-74.

Wynegar, D. (1994) Estimating the potential of international markets. In Ritchie and Goeldner (eds), Travel, Tourism and Hospitality Research, New York: John Wiley \& Sons, pp.597-606.

Zins, A. (1999) Destination portfolios using a European vacation style typology, Journal of Travel and Tourism Marketing, 8(1), pp.1-23. 